\title{
Fully bio-based aliphatic thermoset polyesters via self-catalyzed self-condensation of multifunctional epoxy monomers directly extracted from natural sources
}

\author{
Samer Nameer, Mats Johansson (i)
}

(C) The Author(s) 2017. This article is an open access publication

\begin{abstract}
The use of bio-based raw material is regarded as a sustainable way to address environmental concerns. A naturally occurring monomer, 9,10epoxy-18-hydroxyoctadecanoic acid (EFA), was retrieved from outer birch bark. A series of model experiments revealing relative reaction rates for epoxide, carboxylic acid, and alcohol functional groups was investigated. Real-time Fourier transform infrared spectroscopy and nuclear magnetic resonance were used to follow the different model experiments. The results on the model systems were then compared to the thermoset formation of thermally cured EFA. Finally, the adhesive properties of crosslinked EFA on different substrates were evaluated.
\end{abstract}

Keywords Bio-based monomer, Epoxide, Selfcatalysis, Thermoset

\section{Introduction}

Environmental concerns and a search for more sustainable solutions for the future have driven research efforts in developing new systems for coatings and adhesives. ${ }^{1}$ Issues addressed include development of new, more benign reaction conditions as well as utilization of available bio-based resources to a greater extent. $^{2,3}$ One specific area where this is a true challenge is the formation of thermoset polymers

This paper was presented at the 12 th Coatings Science International Conference (COSI) on June 27-July 1, 2016 in Noordwijk, The Netherlands.

S. Nameer, M. Johansson ( $\square)$

Department of Fibre and Polymer Technology, School of Chemical Sciences and Engineering, KTH Royal Institute of Technology, 10044 Stockholm, Sweden e-mail: matskg@kth.se where most current systems are fossil-based and where it is difficult to find fully bio-based alternatives.

One of the workhorses in thermoset chemistries is epoxy-based resins ranging from glycidyl-based structures to cycloaliphatic epoxides. Epoxy functional thermoset resins have a central role in numerous thermoset applications ranging from composite matrices to organic coatings. ${ }^{4}$ Epoxy functional monomers are used both directly for polymerization or as precursors to make other types of monomers, e.g., acrylates. Epoxides can also react in many ways via chainwise or stepwise polymerization mechanisms. The first can be exemplified with cationic polymerization of cycloaliphatic epoxides ${ }^{5,6}$ and the latter by epoxyamine coupling reactions. ${ }^{7,8}$ Furthermore, the benefit of the epoxy group is that it can undergo reactions with numerous other functional groups such as acids, ${ }^{7,9}$ anhydrides, ${ }^{7,10}$ alcohols, ${ }^{9,11}$ and thiols. ${ }^{12,13}$

One group of bio-based epoxy functional structures that has obtained a significant amount of interest is epoxidized vegetable oils, e.g., epoxidized soybean oil. ${ }^{3,14,15}$ These monomers have one or more secondary epoxy groups situated in the aliphatic chain on the site where the fatty acid initially had the unsaturation. Epoxidized vegetable oils are produced in large volumes and have applications ranging from plasticizing additives in PVC where they also act as acid quenchers, stabilizing the PVC toward thermal degradation, ${ }^{16}$ to cationically polymerizable UV resins. ${ }^{17,18}$ Epoxidized vegetable oils are also used as precursors for other types of thermoset resins such as acrylates, e.g., acrylated epoxidized soybean oil that can be freeradically polymerized to form thermoset structures. ${ }^{19,20}$

One limitation with thermosets based on epoxidized vegetable oils is that the pure aliphatic structure normally gives rather soft materials, i.e., it is difficult to obtain a high glass transition temperature, $T_{\mathrm{g}}$, of the final crosslinked system. The $T_{\mathrm{g}}$ can to some extent be raised by increasing the functionality of the monomer 
by choosing a more unsaturated vegetable oil such as linseed oil as a precursor. Another alternative is to connect epoxidized fatty acids to a multifunctional rigid core molecule instead of the glycerol core present in the vegetable oil. This approach has for example been employed by Webster et al. ${ }^{21,22}$ where they synthesized sucrose-based fatty acid ester thermoset resin. The incorporation of the sucrose unit significantly increased the $T_{\mathrm{g}}$ in comparison with a pure vegetable oil. Johansson et al. ${ }^{23}$ have made modified polyether polyol with epoxidized fatty acids to produce a cationically crosslinkable thermoset structure with improved mechanical performance.

Many epoxidized vegetable oil-based resins are used in combination with various crosslinkers to enhance properties. ${ }^{3}$ Most of these crosslinkers are, however, fossil-based monomers rendering a final thermoset that is only partly bio-based. Recent studies have included naturally based carboxylic acids as crosslinkers to form a fully bio-based thermoset. The main problem with these systems has, however, been the miscibility between the polar carboxylic acid functional crosslinkers and the rather hydrophobic epoxidized fatty acidbased resin. Williams et al. ${ }^{24}$ overcame this by adding a small amount of water as a compatibilizer. Both ${ }^{24,25}$ also demonstrated that a carboxylic acid can catalyze the formation of a secondary ester from a carboxylic acid and a secondary epoxide. Data on the curing performance are presented, but the complete details on the reaction kinetics are not fully understood. The situation is very complex since the system not only starts as a heterogeneous mixture but also is the acid that catalyzes the reaction consumed over time.

An alternative to epoxidized vegetable oils is epoxy functional omega-hydroxyl fatty acids present in large volumes in natural suberin or cutin tissues of different plants. For example, 9,10-epoxy-18-hydroxyoctadecanoic acid (EFA) is found as $10 \%$ of outer birch bark $^{26,27}$ and in significant amounts in the cutin tissue of tea leaves $(40 \%) .{ }^{28}$ EFA, derived from outer birch bark, has been used to make telechelic polymers for thermoset applications. ${ }^{29}$ The EFA monomer was $\alpha, \omega$ oxetane end-capped by enzyme catalysis and then crosslinked by photo-polymerization. The possibility of using enzyme catalysis provided mild polymerization conditions where the epoxide group was unharmed and the final network properties could be tuned by the epoxide to oxetane ratio.

One specific structural feature is that EFA contains all the components in the previously described fatty acid systems within the same molecular entity, thus avoiding any compatibility issue. The $\omega$-hydroxyl group will also reduce the softening effect of free chain ends if incorporated into a network structure.

In the present study, we describe how naturally occurring secondary epoxides can be reacted using aliphatic carboxylic acid as both a catalyst and a comonomer. The naturally occurring monomer shows proof of a one-component thermosetting system suitable for thermally curable adhesives.
Model studies on different monomer components have been performed to understand and reveal relative rates of the possible reactions and how this can be employed to design a fully bio-based thermoset resin that can crosslink at elevated temperature using "selfcatalysis."

\section{Experimental}

\section{Materials}

Lauryl acid (LA) (natural, $\geq 98 \%$, FCC, FG) and lauryl alcohol (LOH) were purchased from Sigma-Aldrich. Methyl-9,10-epoxyoctadecanoate (EMO) was retrieved from epoxidized soybean oil kindly provided by Ackross Chemicals. The 9,10-epoxy-18-hydroxyoctadecanoic acid (EFA) was retrieved from outer birch bark (betula pendula) provided from Holmen $\mathrm{AB}$ (c/o Holmen Energi, SE-89180). Chemical structures of the used monomers are presented in Fig. 1. All chemicals were used as received, unless otherwise noted.

\section{Procedures}

Extraction of 9,10-epoxy-18-hydroxyoctadecanoic acid (EFA) from outer birch bark

EFA was retrieved according to previously described methods in the literature with minor changes to optimize the yields as described below. The retrieval of EFA was divided into two steps where the first step was a removal of extractives performed according to a method described in the literature. ${ }^{30}$ The residue of the outer birch bark powder was left to dry: first in air for $24 \mathrm{~h}$ and then in a vacuum oven at $50^{\circ} \mathrm{C}$ for $24 \mathrm{~h}$. The second step was conducted by a modified hydrolysis process previously described in the literature ${ }^{31,32}$ where the dry ground outer birch bark was weighed into a round-bottom flask and impregnated by reduced pressure with $0.8 \mathrm{M} \mathrm{NaOH}$ solution in the ratio of $1 \mathrm{~g}$ bark per $10 \mathrm{~mL}$ solution. The round-bottom flask was then immersed into a $100^{\circ} \mathrm{C}$ oil bath and refluxed under continuous stirring. After $1 \mathrm{~h}$, the round-bottom flask was allowed to cool down to room temperature and the solid residues was separated and removed by

EFA

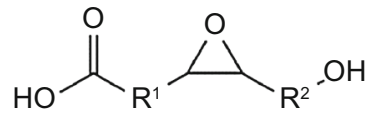<smiles>CI=CO</smiles>

$\mathrm{LOH}$

EMO

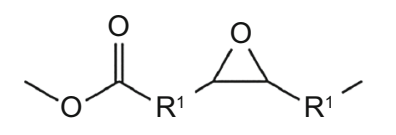<smiles>[R]C(=O)O</smiles>

Fig. 1: Chemical structures of the used monomers and model compounds, $R^{1}=7, R^{2}=8$ and $R^{3}=10$ 
centrifugation. The obtained supernatant was acidified with a $5 \% \mathrm{H}_{2} \mathrm{SO}_{4}$ solution to $\mathrm{pH} 5.7$, and a precipitate was formed. The received precipitate was then separated from the solution by centrifugation and a claylike crude was obtained. The crude product was subjected to 4 washing steps with $100 \mathrm{~mL}$ deionized water on each step. Crude and water were separated by centrifugation each time. Finally, in order to purify the EFA monomer, the crude was recrystallized from toluene. A slightly yellow-colored powder was obtained with a yield of $60-70 \% .{ }^{1} \mathrm{H}$ NMR $(400 \mathrm{MHz}$, $\left.\mathrm{CDCl}_{3}, \delta\right): 3.65\left(\mathbf{2 H}, \mathrm{t},-\mathrm{CH}_{2}-\mathrm{OH}, J=6.59 \mathrm{~Hz}\right), 2.90$ (2H, bs, -CH-O-CH- epoxide), $2.35\left(\mathbf{2 H}, \mathrm{t},-\mathbf{C H}_{2}-\right.$ $\mathrm{CO}-\mathrm{OH}, J=7.45 \mathrm{~Hz}), 1.66-1.26\left(\mathbf{2 6 H}, \mathrm{m},-\mathrm{CH}_{2}-\right)$.

\section{Extraction of methyl 9,10-epoxyoctadecanoate (EMO) from epoxidized linseed oil}

The EMO monomer was obtained by a transesterification reaction according to procedures found in the literature. ${ }^{33}$ Twenty grams of epoxidized linseed oil was dissolved in $248 \mathrm{~mL}$ of $0.02 \mathrm{M} \mathrm{NaOH}$ in methanol. The solution was immersed in a $60^{\circ} \mathrm{C}$ oil bath and refluxed for $1 \mathrm{~h}$. The formed methyl esters were then extracted 4 times in an $n$-heptane/deionized water system (1:1). The organic phase was then dried with $\mathrm{MgSO}_{4}$ and the solvent was evaporated by rotary evaporator. The obtained methyl esters had a yield of $70.5 \mathrm{wt} \%$. Thin-layer chromatography showed the presence of 4 different substances having $R_{\mathrm{f}}$ values of $0.44,0.20,0.04$, and 0 in 10/90 (vol\%) ethyl acetate $/ n$ heptane. The methyl ester mixture was then purified via column chromatography using silica gel and an $n$ heptane/EtOAc gradient elution. ${ }^{1} \mathrm{H}$ NMR proved that the substance having $R_{\mathrm{f}}$ value of 0.20 was EMO monomer. ${ }^{1} \mathrm{H}$ NMR $\left(400 \mathrm{MHz}, \mathrm{CDCl}_{3}, \delta\right): 3.66(3 \mathrm{H}$, s, -O-CH ) $^{2}, 2.89$ (2H, bs, -CH-O-CH- epoxide), 2.30 $\left(\mathbf{2 H}, \mathrm{t},-\mathrm{CH}_{2}-\mathrm{CO}-, J=7.5 \mathrm{~Hz}\right), 1.62\left(\mathbf{2 H}, \mathrm{p},-\mathrm{CH}_{2}-\mathrm{CH}_{2}-\right.$ $\left.\mathrm{CH}_{2}-\mathrm{CO}-J=7.1 \mathrm{~Hz}\right), 1.54-1.20\left(\mathbf{2 6} \mathbf{H}, \mathrm{m},-\mathrm{CH}_{2}-\right)$.

The other substances were confirmed to be methyl stearate $\left(R_{\mathrm{f}} 0.44\right)$, methyl ester with 2 epoxides $\left(R_{\mathrm{f}}\right.$ $0.04)$ and methyl ester with 3 epoxides $\left(R_{\mathrm{f}} 0\right)$. These methyl esters were not used in this study.

\section{Test series on model compounds and crosslinking of EFA}

A series of model experiments were performed to evaluate the different possible reaction pathways of EFA at elevated temperature. Different combinations of $\mathrm{LA}, \mathrm{LOH}$, and, EMO were evaluated with respect to intrinsic reactivities at elevated temperatures. Table 1 presents the different compositions of the test reactions.

The monomers were weighed into a $5-\mathrm{mL}$ roundbottom flask containing a magnetic stirrer and then sealed with a septum. The round-bottom flask was then purged with argon (g) for approximately 20 min before being immersed in an oil bath at $150^{\circ} \mathrm{C}$ for $24 \mathrm{~h}$. Samples for NMR analysis were collected before and after each reaction. One reaction (Table 1, entry 5) containing only EFA was polymerized for $2 \mathrm{~h}$. The reaction gelled after $50 \mathrm{~min}$, and NMR samples were retrieved every $10 \mathrm{~min}$ up to $50 \mathrm{~min}$ before gelation occurred.

All reactions were also studied using real-time FTIR analysis monitoring chemical changes with time on specimens at set temperatures $\left(120,135\right.$, or $\left.150^{\circ} \mathrm{C}\right)$ for 60 min. Reaction no. 3 containing LA and LOH was also run for $120 \mathrm{~min}$, and reaction no. 5 containing only EFA was also run for $180 \mathrm{~min}$. DSC analysis on crosslinked EFA was performed on specimens retrieved from crosslinking in the round-bottom flask.

\section{Crosslinking of EFA-based thermoset between different substrates}

Adhesion properties of EFA were evaluated on different substrates. Two pieces of each substrate (glass, aluminum, steel, Teflon and wood) were glued together to form an overlap joint of approximately $4 \mathrm{~cm}^{2}$. All substrates were cleaned with acetone and ethanol before use. Approximately $10 \mathrm{mg}(2.5 \mathrm{mg}$ $\mathrm{cm}^{-2}$ ) of EFA was applied onto a preheated substrate $\left(150^{\circ} \mathrm{C}\right)$ and then clamped together with the other substrate before it was placed in the oven for $1 \mathrm{~h}$ at $150^{\circ} \mathrm{C}$.

\section{Analytical techniques}

\section{Nuclear magnetic resonance (NMR)}

All NMR spectra were recorded on a Bruker AM 400 at $400 \mathrm{MHz}$. Deuterated chloroform $\left(\mathrm{CDCl}_{3}\right)$ was used as a solvent. The residual $\mathrm{CDCl}_{3}$ solvent peak was used as reference $\left(\delta=7.26 \mathrm{ppm}\right.$ singlet for ${ }^{1} \mathrm{H}$ NMR and $\delta=77.16 \mathrm{ppm}$ as the central line of the triplet for ${ }^{13} \mathrm{C}$ NMR).

Real-time Fourier transform infrared spectroscopy (RTFTIR)

Analyses were recorded on a Perkin Elmer Spectrum 2000 FTIR instrument (Norwalk, CT) equipped with a single reflection (ATR: attenuated total reflection) accessory unit (Golden Gate) from Graseby Specac LTD (Kent, England) and a TGS detector using the Golden Gate set-up. Recorded data were processed in Spectrum software from PerkinElmer. RT-FTIR (relative reactivity studies) data were recorded at an optimized scanning rate of 1 scan per $6 \mathrm{~s}$ with a resolution of $4.0 \mathrm{~cm}^{-1}$ and were processed on Time Base $^{\circledR}$ software from Perkin Elmer. The Golden Gate accessory unit was equipped with a temperature control (Specac, Heated Golden Gate Controller). 
Table 1: Reaction compositions for model test series and crosslinking of EFA

\begin{tabular}{|c|c|c|c|c|c|c|c|c|}
\hline \multirow[t]{2}{*}{ Reaction no. } & \multicolumn{2}{|c|}{ EMO } & \multicolumn{2}{|c|}{ LA } & \multicolumn{2}{|c|}{$\mathrm{LOH}$} & \multicolumn{2}{|c|}{ EFA } \\
\hline & $(\mathrm{mmol})$ & (g) & $(\mathrm{mmol})$ & (g) & $(\mathrm{mmol})$ & (g) & $(\mathrm{mmol})$ & (g) \\
\hline 1 & 1.28 & 0.40 & 1.28 & 0.26 & - & - & - & - \\
\hline 2 & 1.28 & 0.40 & - & - & 1.28 & 0.24 & - & - \\
\hline 3 & - & - & 2.50 & 0.50 & 2.50 & 0.47 & - & - \\
\hline 4 & 1.28 & 0.40 & 1.28 & 0.26 & 1.28 & 0.24 & - & - \\
\hline 5 & & & & & & & 0.32 & 0.10 \\
\hline
\end{tabular}

The temperature on the Golden Gate was set to desired temperature and a background scan was made before conducting each experiment. The sample was put directly on the crystal and a plain glass cover slide placed onto the sample. The characteristic peaks from the RT-FTIR measurements were compared with characteristic infrared absorption bands in reference (34).

\section{Differential scanning calorimetry (DSC)}

The thermal analyses were carried out on a Mettler Toledo DSC-1 equipped with Gas Controller GC100. For the analysis, approximately $5-10 \mathrm{mg}$ of each sample were weighed into aluminum crucibles of $100 \mu \mathrm{L}$. The data were collected using a heating/cooling rate of $5^{\circ} \mathrm{C} \mathrm{min}^{-1}$ from -40 to $150^{\circ} \mathrm{C}$ with $5 \mathrm{~min}$ isotherms. All analyses were carried out in nitrogen gas atmosphere of $30 \mathrm{~mL} \mathrm{~min}{ }^{-1}$. The evaluation of acquired data was done using STARe Excellence Software. The glass transition temperature $\left(T_{\mathrm{g}}\right)$ was reported as the midpoint of the heat capacity change and was acquired from the second heating scan.

\section{Results and discussion}

The purpose of the present work was to demonstrate the possibility of using naturally occurring multifunctional monomers as self-crosslinkable thermosets without the use of curing catalysts. A set of well-defined model systems was evaluated to reveal details on the curing scheme for the multifunctional epoxy monomer. It should be emphasized that all components in the present study are fully miscible, thus avoiding any effect of phase separation (Scheme 1).

\section{Relative reaction rates in model systems}

The EFA monomer contained a hydroxyl, a primary carboxylic acid, and a secondary aliphatic epoxide while a series of experiments were performed in reactions 1-4 (Table 1) to reveal which and how fast reactions did occur at elevated temperatures. The reactions were monitored "in situ" using RT-FTIR as well as intermittently with NMR on samples taken out at specific intervals. The choice of model compounds was made to ensure full compatibility between the components in the liquid state, i.e., fully homogeneous systems were analyzed. The reaction temperature was set to $150^{\circ} \mathrm{C}$ since this was found to give suitable reaction rates after an initial screening test.

\section{The epoxide-carboxylic acid reaction, reaction no. 1}

The epoxide-carboxylic acid reaction (Table 1, entry 1) was studied by both NMR and RT-FTIR. The NMR results showed proof of the ring-opening reaction by the disappearance of epoxide protons and carbon peak $g$ at $2.90 \mathrm{ppm}$ and $G$ at $57.39 \mathrm{ppm}$, respectively (Fig. 2). It was further seen that two new peaks, $i$ (3.56 ppm) and $h(4.80 \mathrm{ppm})$ on ${ }^{1} \mathrm{H}$ NMR, and $I$ $(72.55 \mathrm{ppm})$ and $H(76.30 \mathrm{ppm})$ on ${ }^{13} \mathrm{C}$ NMR, emerged. These protons were assigned to protons on hydroxyl branched carbon of the fatty acid chain and the ester branched carbon of the fatty acid chain, respectively. ${ }^{35,36}$

A ring-opening reaction between an acid and epoxide would create a secondary alcohol and an ester. $^{24,25,36}$ To confirm this, reaction characteristic carbonyl regions for acids $\left(1740-1700 \mathrm{~cm}^{-1}\right)$ and esters $\left(1750-1725 \mathrm{~cm}^{-1}\right)$ were monitored. The reaction was further confirmed by RT-FTIR by the depletion of the absorption band at $1714 \mathrm{~cm}^{-1}$ and an increase in absorption band at $1740 \mathrm{~cm}^{-1}$ which correlates with the free acid and an ester, respectively (Fig. 3). The formed alcohol group was observed by the increase in absorption band at $3530 \mathrm{~cm}^{-1}$. Epoxide compounds have a weak absorption band in the region of 950$750 \mathrm{~cm}^{-1}$. Although a small decrease was seen in that particular area, it was difficult to quantify these changes due to overlapping from other bands in the fingerprint region. The results indicate that the reaction was catalyzed by a protonation of the epoxide ring followed by an attack of a carboxylate anion forming a new ester bond and an alcohol. However, there was no evidence of side reactions such as generation of linear ether groups (e.g., from alcohol attacking a protonated epoxide or cationic homopolymerization of epoxides) on NMR or RT-FTIR. Another possible reaction is the reaction between the secondary hydroxyl formed by the addition of acid to the epoxide reacting further 


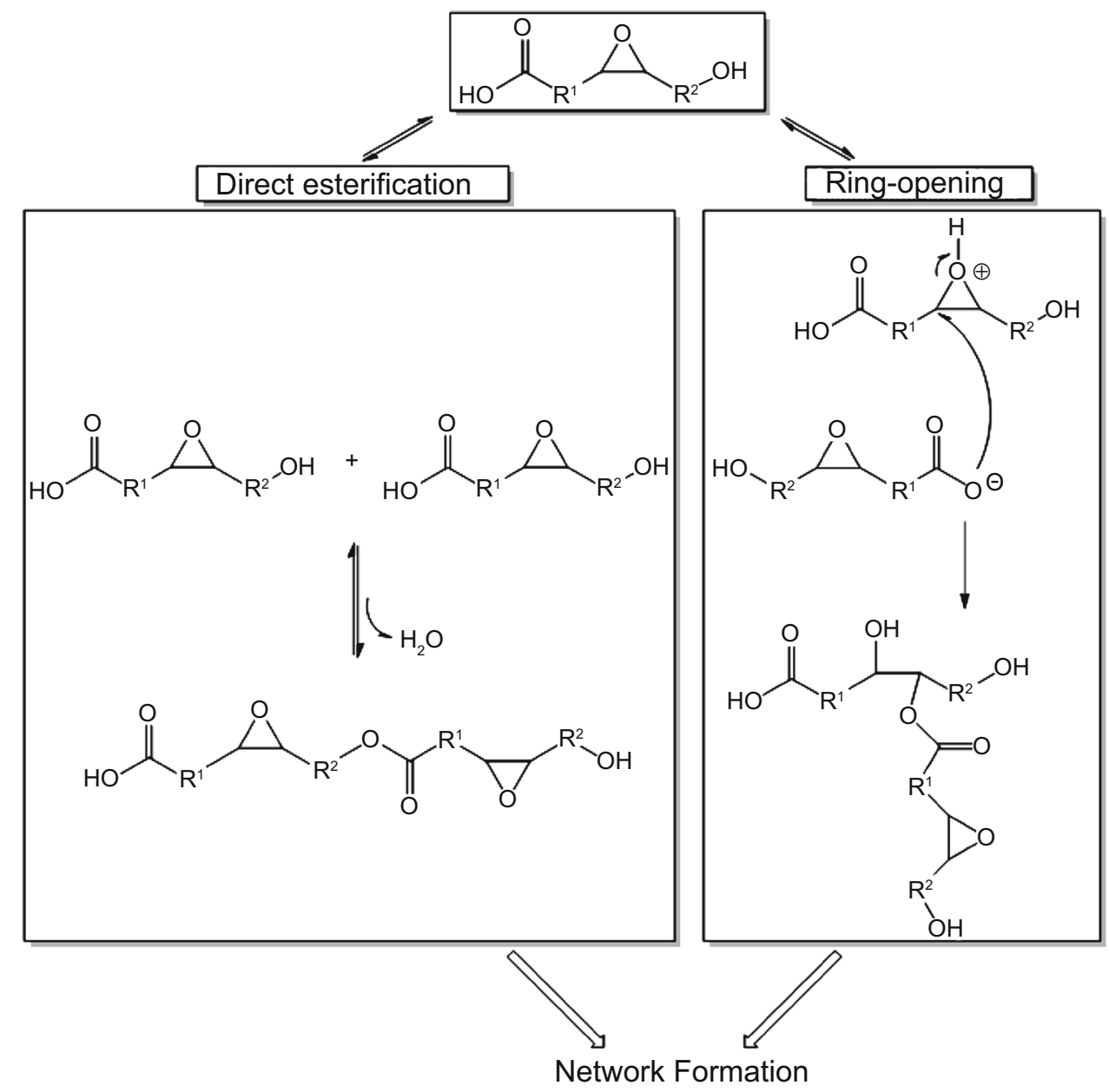

Scheme 1: Suggested mechanism for curing of EFA at elevated temperature. To the left: direct esterification and to the right: ring-opening of the epoxide where $R^{1}=7$ and $R^{2}=8$
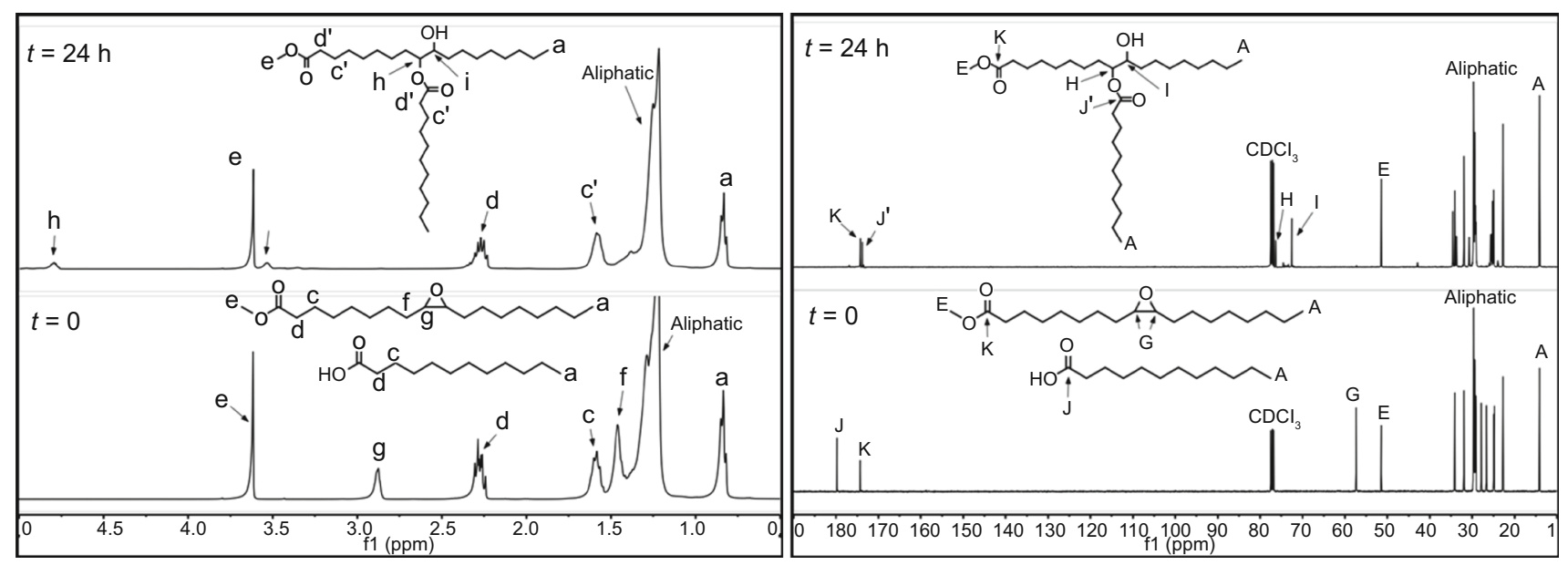

Fig. 2: ${ }^{1} \mathrm{H}$ NMR and ${ }^{13} \mathrm{C}$ NMR of reaction no. 1 before and after thermal treatment at $150^{\circ} \mathrm{C}$ for $24 \mathrm{~h}$ 


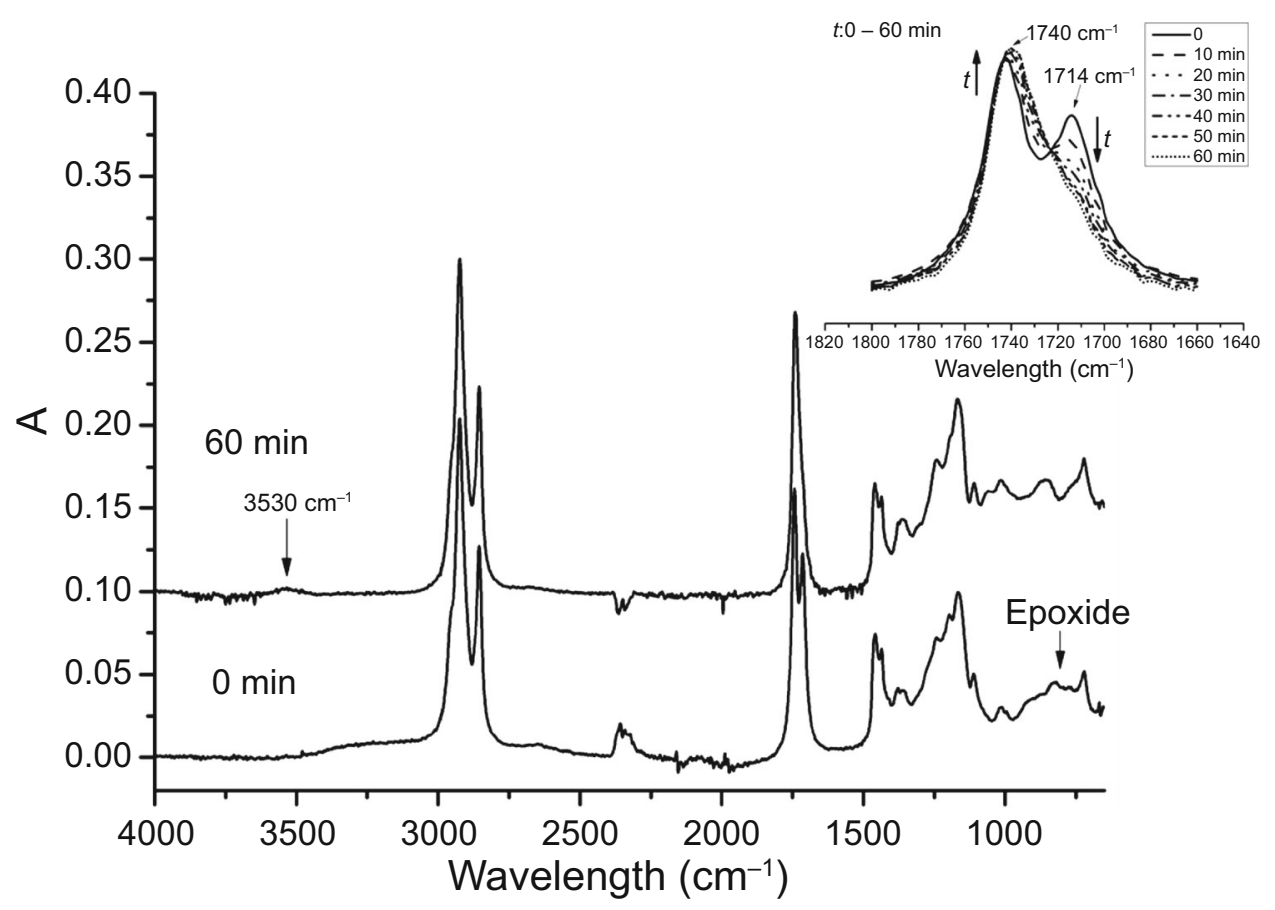

Fig. 3: RT-FTIR of reaction no. 1 as a function of time at $150^{\circ} \mathrm{C}$

either with the carboxylic acid or the methyl ester. However, the NMR data did not indicate any detectable amount of these reactions occurring under set conditions.

\section{The epoxide-alcohol reaction, reaction no. 2}

It is well known that hydroxyl groups can perform a nucleophilic attack on epoxides under acidic conditions and form an ether linkage. ${ }^{9}$ The results from reaction containing hydroxyls and epoxides (Table 1, entry 2) under neutral conditions, however, showed no detectable reaction between the hydroxyl group and the epoxide as studied with NMR or RT-FTIR.

\section{The direct esterification reaction, reaction no. 3}

Apart from the protonation of the epoxide, EFA has the possibility of a direct esterification reaction between the acid and the alcohol group. In order to evaluate the possibility of esterification at elevated temperature, a model experiment containing only acid (LA) and alcohol (LOH) was conducted (Table 1, entry 3). The performed experiment suggests that an esterification occurs by the appearance of peaks $d^{\prime}$ and $p^{\prime}$ at $2.28 \mathrm{ppm}$ and $4.05 \mathrm{ppm}$, respectively. Characteristic peaks corresponding to the monomers LA (2.35 ppm, peak $d$ ) and LOH (3.60 ppm, peak $p$ ) both disappear (Fig. 4). The esterification reaction was also confirmed by RT-FTIR by the depletion of the absorption band corresponding to the acid $\left(1715 \mathrm{~cm}^{-1}\right)$ and an increase in the peak corresponding to the ester $\left(1740 \mathrm{~cm}^{-1}\right)$ (Fig. 4).

Comparing the RT-FTIR results of reaction no. 1 and reaction no. 3 (Figs. 3 and 4), it is observed that the ring-opening reaction, adding a carboxylic acid to the epoxide, is faster than the direct esterification reaction. The conversion after $40 \mathrm{~min}$ of the ringopening reaction was over $90 \%$ while the esterification only reached approximately $70 \%$ after $2 \mathrm{~h}$. Although different in rates, one should note that the differences are within the same order of magnitude.

\section{The epoxide-carboxylic acid vs direct esterification reaction, reaction no. 4}

By knowing the trends from each reaction, it was easier to follow the reaction containing all three different functional groups present, i.e., EMO, LA, and $\mathrm{LOH}$ (Table 1, entry 4). As the previous model experiments depicted, a ring-opening reaction and an esterification reaction occurred but this time in parallel with each other, as evidenced by NMR and RT-FTIR (Fig. 5). The relative conversion differences at higher conversions are less than initially foreseen by the tests on reactions no. 1-3. The explanation for this is mainly due to the change in stoichiometry as a function of conversion. A more rapid epoxide-carboxylic acid reaction also leads to a more rapid depletion of the EMO monomer while the relative concentration of LOH increases, thus promoting the direct esterification at higher conversions. 


\section{The reaction of $\mathrm{EFA}$ at elevated temperature toward a thermoset structure}

Finally, the polymerization of EFA was monitored under the same reaction conditions (Table 1, entry 5). A similar trend as compared to the model experiments on reaction no. 4 was observed by ${ }^{1} \mathrm{H}$ NMR and RTFTIR analysis (Fig. 6). Peaks arising at 3.57 ppm (i) and $4.83 \mathrm{ppm}(h)$ confirming the epoxide-carboxylic acid reaction were observed. Furthermore, the epoxide characteristic peak at $2.90 \mathrm{ppm}(g)$ was depleted, showing more proof of the epoxy ring-opening reaction. The suggested direct esterification reaction between the acid and the alcohol in EFA was evidenced by the rise of the peak at $4.05 \mathrm{ppm}\left(p^{\prime}\right)$. Moreover, the RT-FTIR showed the same trend regarding the depletion of the acid $\left(1712 \mathrm{~cm}^{-1}\right)$ and an increase in the ester vibration $\left(1730 \mathrm{~cm}^{-1}\right)$ which was observed in both direct esterification and epoxy ring-opening reaction.
It is most likely that the main reaction is when the acid in EFA acts as a catalyst and initiates the reaction by protonating the epoxide. The protonated epoxide becomes more susceptible to nucleophilic attack from a carboxylate anion, and a ring-opening reaction occurs forming an ester and alcohol group. As evidenced by the model experiments, an esterification reaction is also possible in parallel with the main reaction at a slower rate. Apart from the mentioned reactions a protonated epoxide can be attacked by an alcohol group which limits the evolution of "dangling ends" in the network material.

It should also be noted that NMR analysis was only possible to perform up to $50 \mathrm{~min}$ since the reaction after this point became an insoluble gel. It can furthermore be noted that all carboxylic acids eventually were consumed while unreacted epoxides and hydroxyls to some extent remained in the final thermoset. One feature worth mentioning is that the carboxylic acid acts both as a catalyst as well as a monomer which is consumed during the crosslinking.
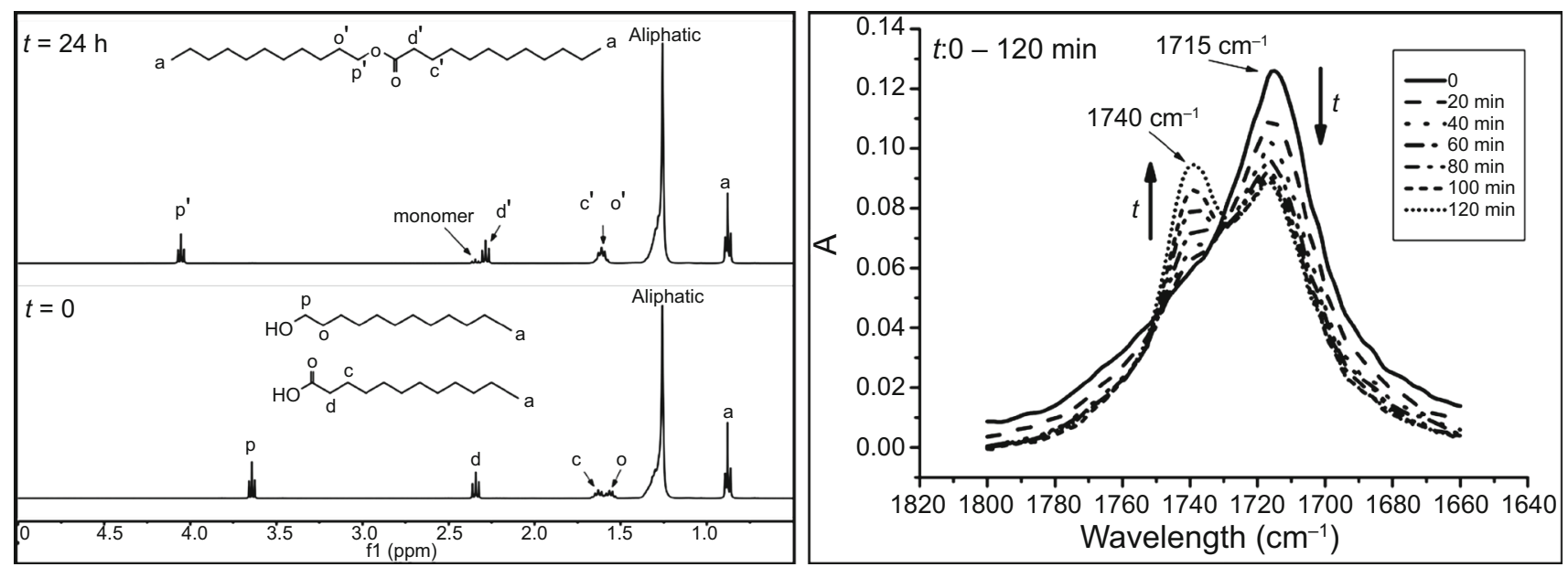

Fig. 4: ${ }^{1} \mathrm{H}$ NMR and RT-FTIR spectra for reaction no. 3 before and after reaction
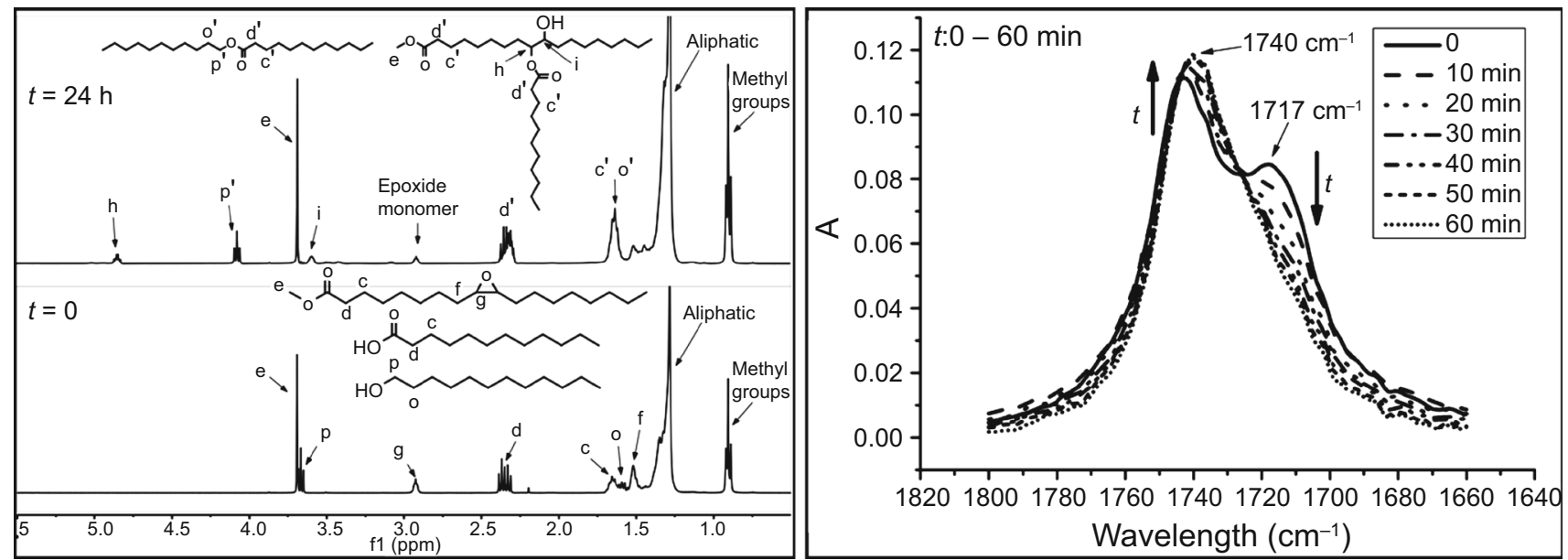

Fig. 5: ${ }^{1} \mathrm{H}$ NMR and RT-FTIR spectra for reaction no. 4 before and after reaction 

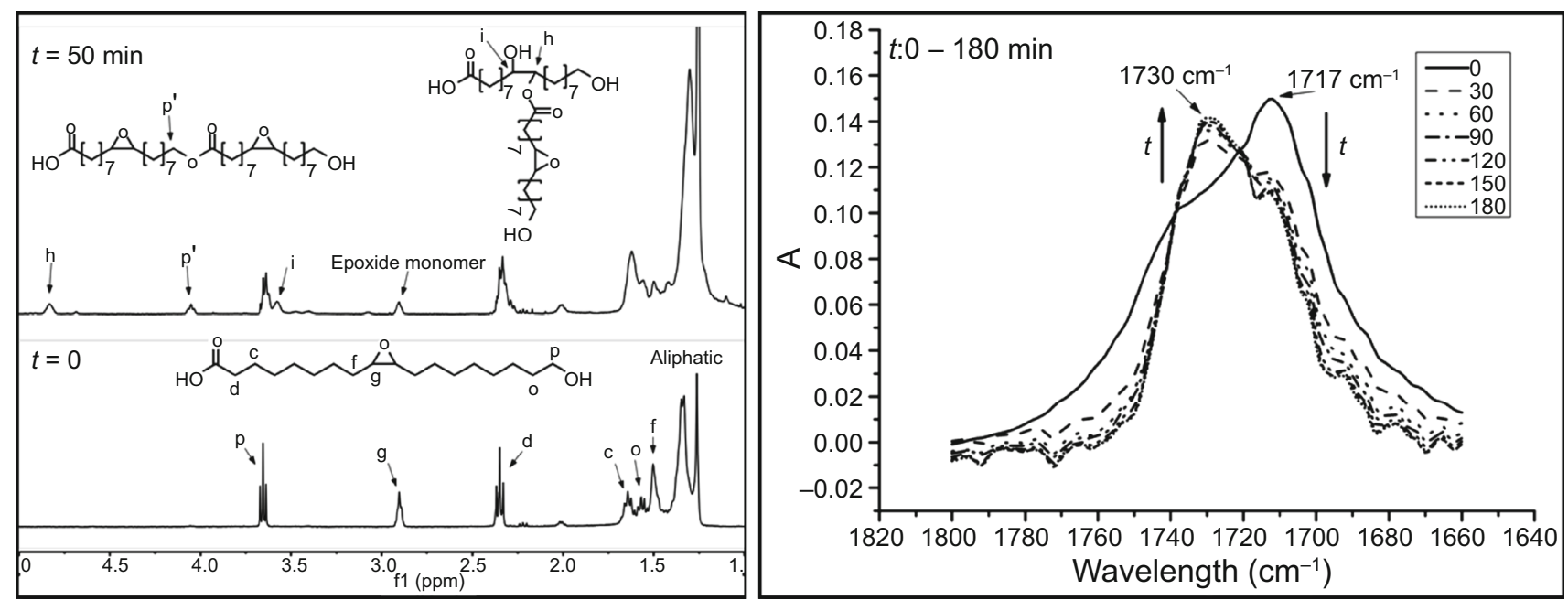

Fig. 6: ${ }^{1} \mathrm{H}$ NMR and RT-FTIR spectra for reaction no. 5 before and after reaction
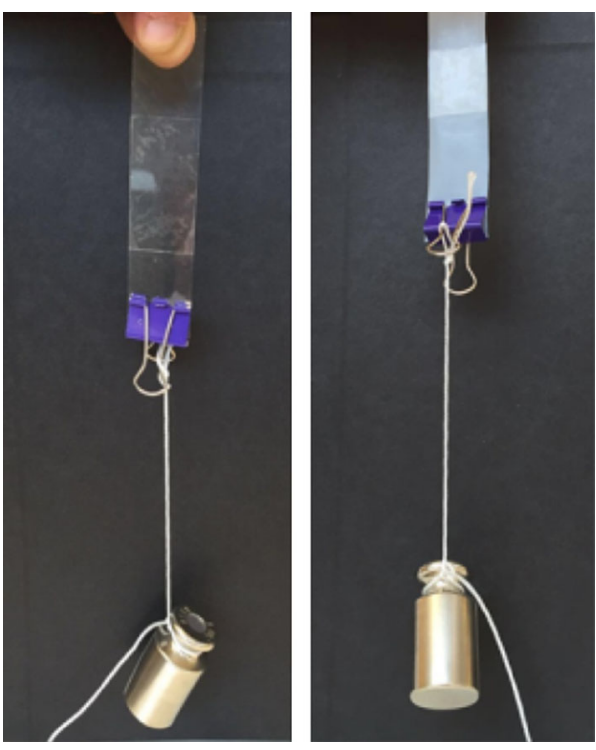

Fig. 7: Glued samples subjected to a static load of $100 \mathrm{~g}$. Glass substrates to the left and Teflon film to the right

This would imply that the reaction gradually slows down at higher conversions, but it is still shown that high conversions can be reached at elevated temperature and not too lengthy reaction times.

\section{Crosslinking of EFA-based thermoset between different substrates}

The adhesive properties of EFA were conducted by gluing two pieces of the same substrate together. The adhesive properties were evaluated on wood veneers, glass, aluminum, Teflon, and steel. The adhesive performance on wood was poor since the monomer became too low viscous when heated with subsequent penetration into the substrate as a consequence and then curing inside the veneer instead of in between the veneers. On the other hand, EFA showed promising adhesion to all the other substrates as simply determined by putting a $100 \mathrm{~g}$ load on the joint substrates (Fig. 7). DSC analysis of the crosslinked EFA monomer revealed no crystallinity and a $T_{\mathrm{g}}$ of $-5 \pm 2{ }^{\circ} \mathrm{C}$ measured on the second heating.

\section{Conclusions}

In this work, it has been shown that a naturally occurring epoxy fatty acid can be used for thermoset applications. The monomers structural feature presents a suitable opportunity for a one-component thermally curable adhesive system. Moreover, compatibility issues can be circumvented by using this monomer due to the fact that the monomer is acting as both catalyst and co-monomer in the curing reaction. Relative rates of possible reactions were studied by different model reactions. Both a ring-opening reaction and a direct esterification reaction can occur at elevated temperatures when all the mentioned functionalities are present in the reaction mixture. Adhesive properties of EFA on different substrates were also evaluated and showed promising results.

Acknowledgments This work has been supported by the Swedish research council, FORMAS (Grant Number 211-2013-70).

Open Access This article is distributed under the terms of the Creative Commons Attribution 4.0 International License (http://creativecommons.org/licenses/by/4.0/), which permits unrestricted use, distribution, and reproduction in any medium, provided you give appropriate credit to the original author(s) and the source, provide a link to the 
Creative Commons license, and indicate if changes were made.

\section{References}

1. Clark, JH, "Green Chemistry for the Second Generation Biorefinery-Sustainable Chemical Manufacturing Based on Biomass." J. Chem. Technol. Biotechnol., 82 (7) 603-609 (2007)

2. Lligadas, G, et al., "Renewable Polymeric Materials from Vegetable Oils: A Perspective." Mater. Today, 16 (9) 337343 (2013)

3. Meier, MAR, Metzger, JO, Schubert, US, "Plant Oil Renewable Resources as Green Alternatives in Polymer Science." Chem. Soc. Rev., 36 (11) 1788-1802 (2007)

4. Ellis, B, Chemistry and Technology of Epoxy Resins. Springer, Berlin, 1993

5. Crivello, JV, Varlemann, U, "The Synthesis and Study of the Photoinitiated Cationic Polymerization of Novel Cycloaliphatic Epoxides." J. Polym. Sci. Part A: Polym. Chem., 33 (14) 2463-2471 (1995)

6. Decker, C, Nguyen Thi Viet, T, Pham Thi, H, "Photoinitiated Cationic Polymerization of Epoxides." Polym. Int., 50 (9) 986-997 (2001)

7. Barton, JM, "The Application Of Differential Scanning Calorimetry (DSC) to the Study of Epoxy Resin Curing Reactions." In: Dusek, K (ed.) Epoxy Resins and Composites I. pp. 111-154. Springer, Berlin, 1985

8. Rozenberg, BA, "Kinetics, Thermodynamics and Mechanism of Reactions of Epoxy Oligomers with Amines." In: Dušek, K (ed.) Epoxy Resins and Composites II, pp. 113-165. Springer, Berlin, 1986

9. Shechter, L, Wynstra, J, "Glycidyl Ether Reactions with Alcohols, Phenols, Carboxylic Acids, and Acid Anhydrides." Ind. Eng. Chem., 48 (1) 86-93 (1956)

10. Matějka, L, et al., "Curing Epoxy Resins with Anhydrides. Model Reactions and Reaction Mechanism." J. Polym. Sci. Polym. Chem. Ed., 21 (10) 2873-2885 (1983)

11. Crivello, JV, Liu, S, "Photoinitiated Cationic Polymerization of Epoxy Alcohol Monomers." J. Polym. Sci. Part A: Polym. Chem., 38 (3) 389-401 (2000)

12. Seubert, CM, Nichols, ME, "Epoxy Thiol Photolatent Base Clearcoats: Curing and Formulation." J. Coat. Technol. Res., 7 (5) 615-622 (2010)

13. Sangermano, M, Vitale, A, Dietliker, K, "Photolatent Amines Producing a Strong Base as Photocatalyst for the In Situ Preparation of Organic-Inorganic Hybrid Coatings." Polymer, 55 (7) 1628-1635 (2014)

14. Tan, SG, Chow, WS, "Biobased Epoxidized Vegetable Oils and Its Greener Epoxy Blends: A Review." Polym. Plast. Technol. Eng., 49 (15) 1581-1590 (2010)

15. Galià, M, et al., "Vegetable Oil-Based Thermosetting Polymers." Eur. J. Lipid Sci. Technol., 112 (1) 87-96 (2010)

16. Bueno-Ferrer, C, Garrigós, MC, Jiménez, A, "Characterization and Thermal Stability of Poly(Vinyl Chloride) Plasticized with Epoxidized Soybean Oil for Food Packaging." Polym. Degrad. Stab., 95 (11) 2207-2212 (2010)

17. Crivello, JV, Narayan, R, Sternstein, SS, "Fabrication and Mechanical Characterization of Glass Fiber Reinforced UVCured Composites from Epoxidized Vegetable Oils." $J$. Appl. Polym. Sci., 64 (11) 2073-2087 (1997)
18. Thames, SF, Yu, H, "Cationic UV-Cured Coatings of Epoxide-Containing Vegetable Oils." Surf Coat. Technol., 115 (2-3) 208-214 (1999)

19. Grishchuk, S, Karger-Kocsis, J, "Hybrid Thermosets from Vinyl Ester Resin and Acrylated Epoxidized Soybean Oil (AESO)." Express Polym. Lett., 5 (1) 2-11 (2011)

20. Pelletier, H, Belgacem, N, Gandini, A, "Acrylated Vegetable Oils as Photocrosslinkable Materials." J. Appl. Polym. Sci., 99 (6) 3218-3221 (2006)

21. Pan, X, Sengupta, P, Webster, DC, "Novel Biobased Epoxy Compounds: Epoxidized Sucrose Esters of Fatty Acids." Green Chem., 13 (4) 965-975 (2011)

22. Pan, X, Sengupta, P, Webster, DC, "High Biobased Content Epoxy-Anhydride Thermosets from Epoxidized Sucrose Esters of Fatty Acids." Biomacromolecules, 12 (6) 24162428 (2011)

23. Torron, S, Semlitsch, S, Martinelle, M, Johansson, M, "Biocatalytic Synthesis of Epoxy Resins from Fatty Acids as a Versatile Route for the Formation of Polymer Thermosets with Tunable Properties." Biomacromolecules, 17 4003-4010 (2016)

24. Altuna, FI, Pettarin, V, Williams, RJJ, "Self-Healable Polymer Networks Based on the Cross-Linking of Epoxidised Soybean Oil by an Aqueous Citric Acid Solution." Green Chem., 15 (12) 3360-3366 (2013)

25. La Scala, J, Wool, RP, "Property Analysis of TriglycerideBased Thermosets." Polymer, 46 (1) 61-69 (2005)

26. Krasutsky, PA, "Birch Bark Research and Development." Nat. Prod. Rep., 23 (6) 919-942 (2006)

27. Gandini, A, Neto, CP, Silvestre, AJD, "Suberin: A Promising Renewable Resource for Novel Macromolecular Materials." Prog. Polym. Sci., 31 (10) 878-892 (2006)

28. Tsubaki, S, et al., "Compositional Analysis of Leaf Cuticular Membranes Isolated from Tea Plants (Camellia sinensis L.)." Food Chem., 138 (1) 286-290 (2013)

29. Torron, S, Johansson, M, "Oxetane-Terminated Telechelic Epoxy-Functional Polyesters as Cationically Polymerizable Thermoset Resins: Tuning the Reactivity with Structural Design." J. Polym. Sci. Part A: Polym. Chem., 53 (19) 22582266 (2015)

30. Rüdiger, A, et al., "Chemoenzymatic Route to Renewable Thermosets Based on a Suberin Monomer." J. Renew. Mater., 1 (2) 124-140 (2013)

31. Iversen, T, Nilsson, H, Olsson, A, "A Method for Separating from Suberin and/or Cutin Containing Plants, a Solid and/or Oil Fraction Enriched in cis-9,10-Epoxy-18-Hydroxyoctadecanoic Acid." In: WO2010093320 A1. Google Patents, 2010.

32. Torron, S, et al., "Polymer Thermosets from Multifunctional Polyester Resins Based on Renewable Monomers." Macromol. Chem. Phys., 215 (22) 2198-2206 (2014)

33. Samuelsson, J, Johansson, M, "A Study of Fatty Acid Methyl Esters with Epoxy or Alkyne Functionalities." J. Am. Oil Chem. Soc., 78 (12) 1191-1196 (2001)

34. Socrates, G, Infrared and Raman Characteristic Group Frequencies: Tables and Charts. Wiley, Hoboken, 2004

35. Doll, KM, Erhan, SZ, Sharma, BK, "Method of Making Fatty Acid Ester Derivatives." In: WO2008079901 A2. Google Patents, 2008

36. Ahn, B-JK, Kraft, S, Sun, XS, "Solvent-Free Acid-Catalyzed Ring-Opening of Epoxidized Oleochemicals Using Stearates/Stearic Acid, and Its Applications." J. Agric. Food Chem., 60 (9) 2179-2189 (2012) 